\title{
Lung Inflammatory Myofibroblastic Tumor
}

National Cancer Institute

\section{Source}

National Cancer Institute. Lung Inflammatory Myofibroblastic Tumor. NCI Thesaurus.

Code C39740.

An intermediate fibroblastic neoplasm arising from the lung. It is characterized by the presence of spindle-shaped fibroblasts and myofibroblasts, and a chronic inflammatory infiltrate composed of eosinophils, lymphocytes and plasma cells. 